4. Ивашкевич В.Б. Учет и анализ дебиторской и кредиторской задолженности. / В.Б. Ивашкевич, И.М. Семенова - М.: Бухгалтерский учет, 2015. -С. 192.

5. Коптелов А. Беркович В. Как построить эффективную систему внутреннего контроля / А. Коптелов, В. Беркович //Риск -менеджмент. -2017.-№ 5-6.

6. Парушина Н.В. Анализ дебиторской и кредиторской задолженности / Н.В. Парушина // Бухгалтерский учёт. -2017. -№ 2. С. 54-60.

7. Ржаницына В.С. Учет кредиторской задолженности: оценка, признание и погашение / В.С. Ржаницына // Бухгалтерский учет. -2018. -№17. -С. 8-16.

8. Тарабрина Е.А. Риски в системе бухгалтерского учета, возникающие при взаимодействии с контрагентами и пути их минимизации / Е.А. Тарабрина, И.В. Калюгина // В сборнике: Молодежный вектор развития аграрной науки. Материалы 71-й студенческой научной конференции. Воронежский государственный аграрный университет имени императора Петра I. 2020. - C. 143-149.

\title{
Уртенова М.П. \\ Принципы формирования финансовой информации в бухгалтерской (финансовой) отчетности
}

Северо-Кавказская Государственная Академия

(Россия, Черкесск)

doi: $10.18411 / 1 j-02-2021-97$

idsp: ljournal-02-2021-97

Научный руководитель

Лайпанова 3.M.

\section{Аннотация}

Бухгалтерская (финансовая) отчетность является основным информационным источником для внешних пользователей при принятии инвестиционного рушения. Поэтому представление качественной бухгалтерской информации - одна из приоритетных задач менеджмента компании. Для того чтобы бухгалтерская отчетность соответствовала предъявленным к ней требованиям, при составлении отчетов соблюдаются такие принципы как полное отражение за отчетный период всех хозяйственных операций и результатов инвентаризации; полное совпадение данных синтетического учета и аналитического учета, а также показателей отчетов и балансов с данными синтетического и аналитического учета; осуществление записи хозяйственных операций в бухгалтерском учете только на основании надлежаще оформленных оправдательных документов; правильная оценка статей баланса. Качество информации, содержащейся в финансовой отчетности, волнует руководителей организаций, которые заинтересованы в наличии всей необходимой информации, реально отражающей экономические условия функционирования компании, для принятия грамотных и эффективных управленческих решений.

Ключевые слова: бухгалтерская финансовая отчетность, принципы формирования финансовой информации, основные требования к бухгалтерской отчетности.

\section{Abstract}

Accounting (financial) statements are the main source of information for external users when making investment decisions. Therefore, the presentation of high-quality accounting information is one of the priorities of the company's management. In order for the accounting statements to meet the requirements set out for them, such principles as full reflection of all business operations and inventory results for the reporting period are observed when preparing reports; complete coincidence of the data of synthetic accounting and analytical accounting, as well as indicators of reports and balance sheets with the data of synthetic and analytical accounting; recording of business transactions in accounting only on 
the basis of properly executed supporting documents; correct assessment of balance sheet items. The quality of the information contained in the financial statements is of concern to the heads of organizations who are interested in having all the necessary information that really reflects the economic conditions of the company's functioning, in order to make competent and effective management decisions.

Keywords: accounting financial statements, principles of formation of financial information, basic requirements for accounting statements.

Финансовая отчетность, по сути, является товаром, качество которого определяется содержащейся в ней информацией.

Целью финансовой отчетности общего назначения является предоставление информации о финансовом положении, финансовых результатах деятельности и движении денежных средств компании, полезной для широкого круга пользователей при принятии экономических решений.

Финансовое положение компании раскрывается посредством представления информации об ее активах, обязательствах и капитале (данные баланса); финансовые результаты - путем раскрытия данных о доходах и расходах (данные отчета о финансовых результатах), информация об изменениях в денежных средствах и их эквивалентов содержится в отчете о движении денежных средств.

В информации финансовой отчетности заинтересованы существующие и потенциальные инвесторы, работники, заимодавцы, поставщики и прочие кредиторы, покупатели, фискальные органы, общественность. Однако приоритетными пользователями финансовой отчетности с позиций МФСО являются инвесторы. Международные стандарты исходят из того, что бухгалтерский учет ведется для управления финансовыми вложениями и потоками со стороны инвестора. В этом заключается главное отличие от российского учета, который ведется администратором, действующим в интересах собственника для отражения результатов деятельности объекта собственности.

Другое концептуальное отличие МСФО состоит в том, что усилия бухгалтера в большей мере направлены на формирование достоверной информации о финансовом положении, чем о финансовых результатах. Об этом свидетельствуют и жесткие требования к признанию активов, и требование их оценки по справедливой (рыночной) стоимости.

В соответствии с МСФО выделяют принципы формирования финансовой информации, которые определяют концептуальные основы формирования отчетности.

В Законе о бухгалтерском учете, ПБУ 4/99 «Бухгалтерская отчетность организации» и других документах содержатся основные требования к бухгалтерской отчетности. Так, бухгалтерская отчетность должна давать достоверное и полное представление о финансовом положении организации, финансовых результатах ее деятельности и изменениях в ее финансовом положении. При этом достоверной и полной считается бухгалтерская (финансовая) отчетность, сформированная и составленная исходя из требований, установленных системой правового регулирования бухгалтерского учета в Российской Федерации.

Для того чтобы бухгалтерская отчетность соответствовала предъявляемым к ней требованиям, при составлении бухгалтерских отчетов должно быть обеспечено соблюдение следующих принципов:

1) полное отражение за отчетный период всех хозяйственных операций и результатов инвентаризации всех производственных ресурсов, готовой продукции и расчетов;

2) полное совпадение данных синтетического и аналитического учета, а также показателей отчетов и балансов с данными синтетического и аналитического учета; 
3) осуществление записи хозяйственных операций в бухгалтерском учете только на основании надлежаще оформленных оправдательных документов или приравненных к ним технических носителей информации;

4) правильная оценка статей баланса.

Исходя из этих принципов перед составлением финансовой отчетности предприятие должно:

1) проверить соответствие данных бухгалтерского учета и имеющихся первичных документов;

2) восстановить утраченные первичные документы до составления бухгалтерской отчетности;

3) предупредить материально-ответственных лиц о сроках представления первичных документов;

4) проверить документы по форме;

5) проверить наличие оригиналов документов;

6) провести инвентаризацию имущества, обязательств;

7) проверить правильность использования резервов;

8) откорректировать суммы переходящих остатков;

9) произвести реформацию баланса.

Принципы составления финансовой информации для бухгалтерской (финансовой) отчетности включают в себя также качественные характеристики.

В соответствии с МСФО качественные характеристики являются атрибутами, делающими представляемую в финансовой отчетности информацию полезной для пользователей МСФО выделяют 4 основные качественные характеристики: понятность, сопоставимость, уместность и надежность. Две первые характеристики касаются представления информации, две последующие - ее содержания.

Понятность означает доступность информации для понимания пользователем, имеющим достаточные знания в сфере деловой и экономической деятельности, бухгалтерского учета.

Информация, содержащаяся в финансовой отчетности, должна быть сопоставимой внутри компании по отчетным периодам, а во внешней среде с информацией других компаний. Это позволяет проследить тенденции изменения финансового положения компании и результатах ее деятельности.

Уместной считается информация, влияющая на экономические решения пользователей, помогающая им оценивать прошлые, настоящие и будущие события, подтверждающая или исправляющая прошлые оценки. Качественные характеристики информации тесно взаимосвязаны. На уместность информации значительное влияние оказывает ее существенность.

Существенной считается информация, пропуск или искажение которой могут серьезно повлиять на принятие пользователями управленческих решений. Каждая существенная статья должна представляться в финансовой отчетности отдельно. Несущественные суммы должны включаться в состав более крупных статей аналогичного назначения.

Точных количественных критериев существенности не существует, хотя в отдельных положениях утверждается, что статьи, превышающие 5\% общего итога по данному отчету, следует рассматривать как существенные.

Надежность означает отсутствие в информации существенных ошибок. Залогом надежности информации служит соблюдение следующих условий при ее раскрытии: правдивое представление; преобладание сущности над формой; нейтральность; осмотрительность; полнота; существенность. 
Документально оформленные результаты важны для подтверждения бухгалтерской отчетности и правильности составления налоговой отчетности. результаты инвентаризации должны быть отражены в годовом отчете заключительными записями в декабре. Выявленные излишки и недостатки оформляются актом, сумма выявленного ущерба взыскивается с материальноответственных лиц.

Подготовка стандартов финансовой информации должна происходить в соответствии с основополагающими принципами МСФО, утвержденными Комитетом по международным стандартам (КМСФО).

Качество информации, содержащейся в финансовой отчетности, волнует не только внешних пользователей, являющихся потенциальными инвесторами, но и руководителей организаций, которые заинтересованы в наличии всей необходимой информации, реально отражающей экономические условия функционирования компании, для принятия грамотных и эффективных управленческих решений.

В целях получения такой качественной информации в компаниях разрабатываются и внедряются различные системы учета, позволяющие формировать достоверную отчетность. Отчетность, в свою очередь, являясь одной из функций управления, оказывает влияние на построение системы управления компанией посредством определенных требований и принципов.

Структура финансовой отчетности и форма представления информации, предложенные стандартом, достаточно гибки, что позволяет применять их на предприятиях разных видов деятельности, а также для составления сводной отчетности.

$$
* * *
$$

1. Федеральный закон «О бухгалтерском учете» от 06.12.2011 N 402-Ф3 (последняя редакция)

2. Приказ Минфина РФ от 06.07.1999 N 43н (ред. от 08.11.2010, с изм. от 29.01.2018) «Об утверждении Положения по бухгалтерскому учету «Бухгалтерская отчетность организации» (ПБУ 4/99)»

3. Бабаев Ю. А., Петров А. М. Международные стандарты финансовой отчетности (МСФО). М.: Вузовский учебник: ИНФРА-М, 2018. 398 с.

4. Бухгалтерская финансовая отчетность. Учебник / Под ред. Нечитайло А.И.. - Рн/Д: Феникс, 2017. $144 \mathrm{c.}$

5. Мощенко Н.П. Международные стандарты учета и финансовой отчетности: Учеб. пособие. - М.: Финансы и статистика, 2017. - 272 с.

\section{Столбова Е.Д., Усачева Л.А., Щербакова Т.В. \\ ФРС и ЦБ: методы борьбы с безработицей для стимулирования формирования сбережений населения}

Финансовый университет при Правительстве Российской Федерации (Россия, Москва)

doi: $10.18411 / \mathrm{lj}-02-2021-98$

idsp: ljournal-02-2021-98

\section{Аннотация}

В данной работе рассматриваются основные цели денежно-кредитной политики США и России, инструменты денежно-кредитной политики в условиях исследуемых режимов, а также проводится сравнение проводимых денежно-кредитных политик в этих странах.

Ключевые слова: Безработица, денежно-кредитная политика, режим таргетирования ВВП, режим таргетирования инфляции. 